\title{
Is there common ground for defining a decent social minimum in Europe?
}

\author{
Tim Goedemé, Tess Penne, Otto Swedrup, Karel Van den Bosch and Bérénice Storms ${ }^{1}$
}

\begin{abstract}
Without comparable benchmarks, the cross-national monitoring of the adequacy of minimum income schemes is impossible. However, it is not so straightforward to define what comparability means in this context, and how it should be operationalised. At the minimum, comparability would require that people can have a broadly similar understanding of what adequate social participation means. Obviously, the financial resources that households require at the minimum for adequate social participation vary across time and space due to differences in climate and geographical context, institutional differences, culture and social expectations, as well as variations in the availability, quality and price of essential goods and services. Yet, without a common understanding of what 'adequate social participation' means at a more general level, a benchmark of 'adequacy' that is substantively comparable across countries remains highly elusive. Therefore, in this chapter we explore to what extent there is a common understanding at a more abstract level of 'adequate social participation' in terms of the essential social positions that one should be able to take, and in terms of the needs that should be satisfied to be able to fulfil in an adequate way the social roles associated with these positions. We embed our notion of adequate social participation in some recent philosophical literature on human needs. A large-scale project that involved country teams in all EU Member States, enabled us to develop a 'core list' of social positions, and to validate these as well as a list of intermediate needs across EU Member States using two sources. Formal social expectations have been assessed in terms of commitments of Member States to international conventions and European legal instrumentsand regulations; informal social expectations regarding essential social positions and human needs have subsequently been assessed in three focus group discussions in each of 24 EU capital cities. Overall, the discussions in focus groups across the EU confirm there is quite some common ground with respect to what can be understood under the heading of adequate social participation in terms of essential social positions and needs that should be fulfilled. This provides some evidence that it should be possible to develop benchmarks to assess the adequacy of social protection schemes that are comparable in a meaningful way.
\end{abstract}

\footnotetext{
1 This chapter builds on T. Goedemé et al. Exploring common ground for defining adequate social participation in 24 EU capital cities, CSB Working paper, (Antwerp, University of Antwerp, 2019). We are very grateful to Toomas Kotkas, Frans Pennings, Ingrid Leijten and the participants of the Workshop on Specifying and Securing a Social Minimum in Oñati, Spain, 29-30 June 2017 for thoughtful comments and suggestions. In addition, we would like to thank all country teams that participated in the Pilot project for the development of a common methodology on reference budgets in Europe (see T Goedemé, B Storms, T Penne and K Van den Bosch, The development of a methodology for comparable reference budgets in Europe - Final report of the pilot project, (Brussels, European Commission, 2015). for the full list of researchers involved in the project). Funding by the European Commission (DG Employment and Social Affairs) is gratefully acknowledged (contract no. VC/2013/0554). The views expressed in this chapter are those of the authors and do not necessarily coincide with those of the funders of the underlying research. All remaining errors and shortcomings are our own.
} 


\section{Introduction}

In an era of disappointing poverty trends in Europe ${ }^{2}$, there is an increasingly urgent call to strengthen the social dimension of the EU in order to secure a decent minimum income for all. There have been various soft law initiatives, such as the recently proclaimed European Pillar of Social Rights (see in particular principle 14), that assess a right to adequate minimum income protection. However, the right to a decent social minimum or an adequate minimum income risks remaining a hollow phrase in absence of a pan-European consensus on its normative content. Furthermore, monitoring the adequacy of minimum income schemes at the EU level requires the translation of this theoretical concept into a monetary benchmark that is comparable in a meaningful way across countries. In Europe, usually the at-risk-ofpoverty threshold is used for this purpose. This threshold defines the adequacy benchmark as 60 per cent of national median equivalent disposable household income ${ }^{3}$. This benchmark clearly varies with average living standards across countries, but it is not clear to what extent it refers to what can be considered an adequate minimum income. On the contrary, even though the indicator certainly has its merits, the at-risk-of-poverty indicator is rather arbitrary and assumes that the minimum resources required for a decent living standard are a fixed proportion of median incomes. Consequently, it appears to refer to different levels of adequacy or decency across countries ${ }^{4}$. Is it possible to identify an alternative benchmark that is comparable in a more substantive sense? At least, this would require that the concept of a 'decent living standard' could rely upon a common understanding across Europe. In this chapter, we therefore explore whether such a common understanding is likely to exist. To do so, we focus on the closely related concept of adequate social participation, connect this with recent theories of human needs and use results from a research project on the development of comparable reference budgets in the European Union.

A venerable and internationally widespread method to define a decent social minimum is the reference budget approach. In this research tradition, priced baskets of essential goods and services are constructed, reflecting a certain living standard, such as 'minimum adequate' or 'participation level' standards ${ }^{5}$. One of the main advantages of the approach is that it gives a clear understanding of what is perceived as an acceptable living standard in society, based on different information sources, taking into account the institutional, cultural and social context. Although most European countries have experience with developing reference budgets, the budgets are usually not comparable, as they are developed for varying purposes using a variety of methods ${ }^{6}$. Recently, important steps towards a comparative methodology have been taken in two related European projects ${ }^{7}$, funded by the European Commission and coordinated by the Herman Deleeck Centre for Social Policy (University of Antwerp). This chapter is largely based on the results coming from the 'pilot project on the development of

2 eg B Cantillon, T Goedemé and J Hills, Decent incomes for all. Improving policies in Europe, (New York, OUP, 2019).

3 eg AB Atkinson, B Cantillon, E Marlier and B Nolan, Social Indicators: The EU and Social Inclusion (Oxford, OUP, 2002).

${ }^{4}$ cf T Goedemé, T Penne, T Hufkens, et al. What Does It Mean To Live on the Poverty Threshold? Lessons From Reference Budgets, in B Cantillon, T et al. (eds), Decent incomes for all. (New York: Oxford University Press, 2019).

5 B Storms, T Goedemé, K Van den Bosch, T Penne, N Schuerman and S Stockman, Review of current state of play on reference budget practices at national, regional, and local level, (Brussels, European Commission, 2014).

6 ibid.

7 T Goedemé, B Storms, S Stockman, T Penne and K Van den Bosch, Towards Cross-country Comparable Reference Budgets in Europe: First Results of a Concerted Effort,(2015) European Journal of Social Security (EJSS), 17, 3; T Goedemé, B Storms, T Penne and K Van den Bosch, The development of a methodology for comparable reference budgets in Europe - Final report of the pilot project, (Brussels, European Commission, 2015). 
a methodology for comparable reference budgets in Europe's. In this project, we have developed a common method to construct comparable reference budgets that illustrate what families need for adequate social participation across Europe. Following this methodology, comparable baskets for a healthy diet were constructed in 26 EU Member States, as well as a basket for housing, health and personal care in 8 Member States $^{9}$. In this chapter, we focus on the first step in the process: the search for a common theoretical and normative understanding of what an acceptable minimum means across Europe.

The chapter is structured as follows. First, we elaborate on the concept of adequate social participation. Subsequently, we discuss the theoretical framework that we take as a starting point for listing a number of essential needs that have to be fulfilled to enable social participation. In the next section, we rely on two different methods in order to assess empirically whether there is a common understanding of adequate social participation across Europe. We first assess 'formal' social norms as laid out by international conventions and European legal instruments pertaining to the domain of adequate social participation. Subsequently, we rely on focus group discussions in 24 EU capital cities, carried out in 2015, to explore whether citizens could arrive at a common understanding of 'adequate social participation'. To the best of our knowledge, this was the first qualitative study to assess in a comparative setting simultaneously in many European countries what 'adequate social participation' means and which needs should be fulfilled to be able to participate adequately in society. We conclude that, at least at an abstract level, there seems to be sufficient common ground across EU capital cities for a shared understanding of what adequate social participation should imply. This suggests that it makes sense to continue this line of research and to try to operationalise the concept of adequate social participation in more concrete terms to create a comparable monetary benchmark of adequate incomes in the European Union.

\section{A definition of adequate social participation}

We focus on the concept of adequate social participation, mainly because this concept has received quite some attention in national and international efforts to construct a comparable benchmark to assess the adequacy of income policies, and in particular reference budgets. We define adequate social participation as the ability of people to adequately play (take and make) the various social roles one should be able to play as a member of a particular society ${ }^{10}$. This implies that the physical, psychological and social needs are fulfilled in order to take the different social positions in society in line with the dominant social expectations associated with them, as embodied by the institutions of the society in which one lives, and in such a way that it does not cause harm to one's possibilities to do so in the future. In addition, adequate social participation implies that people should be able to contribute to society not only by playing various social roles, but also by having the opportunity to redefine their social roles.

We would like to highlight briefly several important elements of this definition of adequate social participation. First, we define social roles as the social expectations attached to a

\footnotetext{
8 T Goedemé et al. The development of a methodology for comparable reference budgets in Europe.

9 ibid; K Van den Bosch, T Goedemé, N Schuerman and B Storms, Reference housing costs for adequate dwellings in ten European capitals (2016) Critical Housing Analysis, 3, 1; E Carrillo-Álvarez, T Penne, H Boeckx, B Storms and T Goedemé, Food Reference Budgets as a Potential Policy Tool to Address Food Insecurity (2019) International Journal of Environmental Research and Public Health, 16, 32; T Goedemé et al. What does it mean.

10 B Storms, Referentiebudgetten voor maatschappelijke participatie PhD thesis, (Antwerp, University of Antwerp, 2012).
} 
position that someone in society takes ${ }^{11}$. For the purpose of identifying a concrete monetary benchmark, we focus on social positions defined in broad terms (eg being a mother, being an employee or being a citizen) which society recognises as those that its members should be able to play or should be given the opportunity to take at the minimum.

Second, we define social expectations more broadly as commonly held expectations regarding what people (are able to) think, have and do, as embodied by the institutions of a society. We use the concept of 'institutions' in a dual way ${ }^{12}$ : (1) institutions as socially constructed rules; and (2) institutions as relatively stable patterns of behaviour and interaction, which are often in close interaction with the latter socially constructed rules. As emphasised by Vrooman ${ }^{13}$ one can make a distinction between formal rules, and informal rules that regulate society. In this chapter we focus both on 'formal' and 'informal' social expectations for defining what an adequate minimum is.

Third, we recognise that society is not a fixed social entity. In fact, systems of political authority and cultural expectations may be multi-layered ${ }^{14}$, with some forms of political authority being worldwide, some European, some 'national' and others being rather regional or local. The same is true for dominant cultural expectations. Also, societies can be plural, that is, they can be deeply divided along cultural, religious, ethnic or other lines ${ }^{15}$. In other words, when identifying what could be a decent minimum income, we suggest to pay attention to the dominant social expectations that relate to the place where people live, including their worldwide, European, national, regional and local aspects.

Fourth, in what follows we focus on the material needs of households, assuming that the political and institutional context is organised such that it respects and fosters essential freedoms and is conducive to adequate social participation. Given our focus on EU Member States, we assume that these societal preconditions are in place ${ }^{16}$. Even so, there is (much) room for improvement, especially now that some EU member states have weakened the democratic character of their society ${ }^{17}$ and some reduced the quality of publicly subsidised goods and services ${ }^{18}$.

11 cf 'scripts for social conduct' as in BJ Biddle, Recent Developments in Role Theory (1986) Annual Review of Sociology, 12, 67; GM Platt, Status and Role, Social Psychology of, in NJSB Baltes (ed), International Encyclopedia of the Social \& Behavioral Sciences (Oxford: Pergamon, 2001).

12 cf TR Voss, Institutions, in NJSB Baltes (ed), International Encyclopedia of the Social \& Behavioral Sciences (Oxford: Pergamon, 2001).

${ }^{13}$ CJ Vrooman, Rules of Relief. Institutions of Social Security, and Their Impact (The Hague, SCP, 2009).

14 cf S Mau and R Verwiebe, European Societies. (Bristol, The Policy Press, 2010).

15 eg J Nagata, Plural Societies, in NJSB Baltes (ed), International Encyclopedia.

16 for a discussion of societal preconditions, see for instance L Doyal and I Gough, A Theory of Human Need (Houndmills, Macmillan, 1991).

17 eg A Ágh, The Decline of Democracy in East-Central Europe (2016) Problems of Post-Communism, 63, 277.

18 eg F Cervero-Liceras, M McKee and H Legido-Quigley, The effects of the financial crisis and austerity measures on the Spanish health care system (2015) Health Policy, 119, 100; I Keramidou and L Triantafyllopoulos, The impact of the financial crisis and austerity policies on the service quality of public hospitals in Greece (2018) Health Policy, $122,352$. 


\section{A theoretical framework of human needs ${ }^{19}$}

It is useful to embed our notion of adequate social participation into a broader theoretical framework on human needs. This provides a stronger basis for discussing the needs that should be fulfilled in order to be able to participate adequately in society. In addition, it provides more guidance to reflect upon the necessities for adequate social participation in terms of concrete goods and services as well as the relation between individual and household needs on the one hand, and the characteristics of the social environment on the other. In what follows, we build on different strands in the literature as represented by the works of Len Doyal and Ian Gough, Amartya Sen and Martha Nussbaum. Even though these normative frameworks cannot be fully reconciled, we consider it useful to bring some of the insights of these intellectual strands together. ${ }^{20}$

In several papers Amartya Sen convincingly argues that the living standard should not be understood in terms of utility (the pleasure we derive from something) or opulence (accumulated wealth) but in terms of capabilities: what a person can be or $\mathrm{do}^{21}$. Capabilities have to be distinguished from 'functionings'. Capabilities refer to the total set of possibilities available to persons, while functionings refer to the subset of realised capabilities, implying some choice. egTherefore, in evaluating people's standard of living one should not rely on functionings, but on capabilities. In this spirit, when developing a benchmark for adequate social participation the focus should be on what people should be able to be and do, rather than on what they actually are or do. Further, another strength of the capability approach is that it takes into account the variability in the relation between the means and actual opportunities $^{22}$. People having the same or similar personal resources can have different abilities to achieve certain functionings, for a variety of reasons. egegegegegegIn other words, when developing a benchmark for adequate social participation, it is essential to take the individual situation and social context into account: not everyone requires the same level of financial resources (or even the same goods and services) to achieve the same living standard: this varies with personal and contextual characteristics and circumstances.

In order to determine the essential capabilities for adequate social participation, it would be helpful if one could rely on a list of 'basic capabilities', dealing with human needs and including those capabilities that are essential to live the kind of life that is 'worthy of the dignity of the human being'23. While Sen himself never proposed such a list, we believe that the list formulated by Martha Nussbaum ${ }^{24}$ and the hierarchical model of human needs developed by Len Doyal and Ian Gough ${ }^{25}$ are promising examples, which can be used in the

\footnotetext{
19 This section builds on B Storms, T Goedemé, K Van den Bosch and K Devuyst, Towards a common framework for developing cross-nationally comparable reference budgets in Europe, (Antwerp, Herman Deleeck Centre for Social Policy - University of Antwerp, 2013)..

20 The capability approach links in several ways to legal theory on socio-economic rights, which we highlight below in relation to formal social expectations. For example, David Bilchitz takes his starting point from the writings of Sen and Nussbaum when setting up a theoretical framework to analyse and discuss the justification and enforcement of socio-economic rights. D Bilchitz, Poverty and Fundamental Rights, (Oxford, OUP, 2007).

21 eg A Sen, Choice, Welfare and Measurement (Oxford, Blackwell, 1982); A Sen, The Standard of Living (Cambridge, CUP, 1987).; A Sen, Capability and Well-being, in MC Nussbaum and A Sen (eds), The Quality of LIfe (Oxford:

Clarendon Press, 1993).

22 eg A Sen, Poor, Relatively Speaking,(1983) Oxford Economic Papers, 35, 153.

23 M Nussbaum, Women and Human Development, (Cambridge, CUP, 2000).

24 ibid.

25 L Doyal and I Gough, A Theory of Human Need (Houndmills, Macmillan, 1991).
} 
operationalization of the minimum acceptable way of life ${ }^{26}$. To give people the ability to fully participate in society (Doyal and Gough) or to live a flourishing life (Nussbaum), both put forward the same 'universal needs' or 'basic capabilities' namely physical health ('bodily integrity') and autonomy of agency ('practical reason'), which is closely matched to the need for meaningful social bonding ('affiliation'). An important difference between these theories is that Nussbaum's list consists mainly of what she calls 'combined capabilities', which include also the suitable external conditions for the exercise of functions, while Doyal \& Gough make a clear distinction between universal human needs and the requisite universal societal preconditions. Given that for our purposes this distinction is very useful, we build primarily on Doyal and Gough's work.

We slightly modified Doyal and Gough's original list of intermediate needs to adapt it to the current European context and our purpose of creating reference budgets that could provide a monetary benchmark for adequate social participation ${ }^{27}$. Of course, such a list of needs is not sacrosanct, and could be organised differently, but it has proven to serve usefully our purposes for developing reference budgets. Also, it should be stressed that most of the elements covered by this list can also be recognised in other attempts to define the minimum for adequate social participation, a life in accordance with human dignity, a 'flourishing life', or 'ends of development'28. ${ }^{29}$

Our proposed list includes the following needs: To live healthily and act autonomously, people need a balanced diet. Food and nutrition play a decisive role in the maintenance of good health and in the prevention of various diseases. Besides healthy food, people also need suitable clothing. Clothes serve different purposes in European societies, for instance, offering protection against the weather elements and providing individuals with a certain identity. Like food and clothing, adequate personal hygiene and accessible healthcare are essential intermediate needs that must be fulfilled if an individual is to participate in society. Proper hygiene serves two important purposes. Primarily, it contributes to maintaining a good health by combating infectious microorganisms, both at a personal level and in relation to individuals' environment. Second, personal hygiene serves a psychological and social purpose. Without adequate personal hygiene, there is a danger of social exclusion due to a perceived failure to adhere to the social norm. A next intermediate need that must be met in order for people to be able to live healthy and autonomous lives is that of adequate housing. Each dwelling must fulfil three universal criteria such that the health of the occupants would not be jeopardised ${ }^{30}$. First, the dwelling must offer its occupants security and protection, both against the elements and against bearers of disease. Second, a dwelling must be conducive to a hygienic lifestyle. Third, it must be sufficiently spacious to allow the activities that are required

\footnotetext{
${ }^{26}$ Note that both texts were developed independently of each other. For a discussion of the similarities and differences, see in particular I Gough, Lists and thresholds in F Comim and MC Nussbaum (eds), Capabilities, Gender, Equality (Cambridge, CUP, 2014).

27 A brief literature review of the relevance of each of these intermediate needs can be found in Goedemé et al. Towards Cross-country Comparable Reference Budgets; and Goedemé et al. The development of a methodology.

28 cf S Alkire, Dimensions of Human Development (2002) World Development, 30, 181; MC Nussbaum, Creating Capabilities: The Human Development Approach (Cambridge, HUP, 2011).
}

${ }^{29}$ It should also be mentioned that, regardless of the views proposed in political theory and philosophy on the normative basis for a minimum, several of the needs listed below are needs that can be considered at the foundation of economic and social rights. Katharine G. Young presents different approaches to defining a minimum core, 'giving content to economic and social rights'. One of the approaches described by Young is one that relies on 'the "basic needs of rights- holders as a sufficiently determinable standard for the minimum core.' K G. Young, 'The Minimum Core of Economic and Social Rights: A Concept in Search of Content', Yale Journal of International Law (2008), 33, No. 1.

30 L Doyal and I Gough, A Theory, p196-197. 
for meeting the 'intermediate' needs, such as preparing and eating food, washing, maintaining social relations and rest and leisure.

Even though all 'intermediate' needs are related to both health and autonomy, while the first five needs are primarily relevant for health, the next five refer mainly to autonomy and are more culturally sensitive. To be able to act autonomously as adults, individuals must have experienced security in childhood. Doyal and Gough outline four more or less universal psychosocial needs that must be fulfilled for children and youngsters anywhere in the world to experience adequate security in childhood. According to them, all children need love. They also require new experiences in order to be able to develop cognitively, emotionally and socially. Furthermore, all children need praise, recognition and positive feedback. Finally, all children need a gradual broadening of responsibilities ${ }^{31}$. Beside security in childhood, people must be able to maintain meaningful social relationships. After all, humans are social creatures and they have a fundamental need for social connectedness. It is through daily contacts with relatives, neighbours and friends that individuals are, from their childhood, familiarised with the ideas, values and norms of the culture and society in which they live. People are also social creatures out of need. Even if individuals are adequately supported by qualitatively satisfactory provisions, they are confronted daily with all kinds of practical problems or issues that can only be resolved if they possess the necessary knowledge and skills or are able to acquire them, or by calling on help from others. Other problems may require emotional or practical support. Although the maintenance of mutual relationships primarily requires cultural capital, people also need some minimal economic resources to meet each other. Turning from the social to the cognitive component of personal autonomy, an eighth intermediate need is related to the capability of lifelong learning. In modern societies, both employability and active citizenship are dependent upon having adequate social competences for taking part in and contributing to economic and social life. A next intermediate need that one has to take account of in order to guarantee people full social participation is the need for rest and leisure. Rest allows the body and mind to recuperate and recover, while leisure contributes to physical, social, and emotional health ${ }^{32}$. Furthermore, to lead an autonomous life, people need a basic degree of economic and physical security. Finally, people need to be mobile to fulfil their various social roles adequately (eg to go to work, visit friends, or go shopping). As is true for the other intermediate needs, the minimal mobility requirements depend on the individual's living situation (eg health, employment) as well as on the structural societal conditions (eg availability of public transport).

\section{Common ground across EU Member States for defining adequate social participation}

In the previous section we have defined a list of essential human needs based on a theoretical framework on social participation. However, if the concept of 'adequate social participation' is to be used for meaningful comparative research, at the very least there should be some common understanding of what 'adequate social participation' is across EU Member States. egIf fundamentally different social positions and needs are associated with adequate social participation in different EU Member States, comparability risks being a hollow term. In what follows we briefly illustrate the approach that we have followed, without claiming completeness.

\footnotetext{
31 WHO, Manuals on Child Mental Health and Psychosocial Development (Geneva, WHO, 1982).

$32 \mathrm{eg}$ D Coleman and SE Isoahola, Leisure and health - the role of social support and self-determination (1993) Journal of Leisure Research, 2, 111.
} 


\section{Methodological considerations}

We have validated commonalities across EU Member States on the basis of two sources: (1) formal social expectations have been assessed in terms of commitments of Member States to international conventions and European legal instruments; (2) informal social expectations have subsequently been assessed in three focus group discussions in each of the participating countries.

To assess formal social expectations, we turn to some relevant legal sources at the European level as a way of evaluating to what extent there is any formal common ground to be found. We are, as mentioned above, not claiming to do a full investigation into the different legal provisions highlighted below, but rather look at relevant legal sources in an explorative manner as a first step towards identifying a common ground. Obviously, formal social expectations can be stronger or weaker. For instance, some countries may sign up to international agreements, but fail to properly translate their promises into national legislation, concrete policies and law enforcement. Therefore, what we identify as common ground on the basis of a textual reading of international declarations or covenants should not be interpreted as 'having exactly the same formal social expectations'. The starting point for this exercise was the list of needs derived from Doyal and Gough's Theory of Human Need. In a first step we identified the relevant legal provisions which relate to our list of 'intermediate needs', as a way of pointing to the existence of a normative basis and thus some common ground between EU member states on these issues. Similarly, we have identified a formal common ground for a core list of social positions based on a reading of relevant EU legal instruments. The connection between essential needs and the universe of social rights might be a bit more straightforward, merely judging from the exercise of assessing different social positions from the legal instruments chosen for this study. ${ }^{33}$ However, identifying a formal common list of social positions allows for a more concrete discussion on what is needed for social participation, which was used in the focus group discussions.

In order to get more insight into the informal social expectations in society, three focus groups were conducted in each of $24 \mathrm{EU}$ capital cities $^{34}$. We have opted for the focus group technique as it allows for gaining more insight into the well-considered views of citizens after some faceto-face discussion with others. This is important, given the rather abstract nature of the exercise and the type of 'common ground' that we try to identify (ie the outcome of a wellreasoned debate). Since needs are socially perceived, informed discussions between different people with different experiences are necessary to stimulate a public perspective on what families minimally need. To stimulate an informed discussion, the participants were informed about the formal social expectations identified in the previous phase of the project. Given the qualitative nature of the exercise, it should be clear that the results are not necessarily representative for the views of the population in each country or capital city: a larger random sample would be required to assess their representativeness. Moreover, the outcome of focus group discussions is very context specific and depends among others on the role of the moderator, the recruitment procedure, the group composition and the specific group dynamics. Therefore, in order to maximise comparability, the process was harmonised through a clear focus group script, containing detailed instructions on recruitment,

\footnotetext{
33 Brinks, Gauri and Shen discuss how 'the rights language can be read to express something presumably universal about human needs', see D Brinks, V Gauri and K Shen Social Rights Constitutionalism: Negotiating the Tension Between the Universal and the Particular (2015) Annual Review of Law and Social Science, 11, 289 (p. 290). They focus on social rights in constitutional texts among other things to review an increased use of social rights language. In their study, they also approach and characterize the legal instruments as empirical material to study if and to what extent social rights are mentioned in domestic constitutions.
}

${ }^{34}$ Some country teams organised two rather than three focus groups. The EU countries not covered by this exercise are Estonia, Ireland, Slovakia and the United Kingdom. 
preparation, organisation, content and analysis. The national partners recruited for each focus group 5 to 11 participants of active age (30-50), through a questionnaire for recruitment, ensuring a mix of different family situations, and a variety of socio-economic backgrounds. We have deliberately chosen to include people with different backgrounds in order to increase the variation of opinions and validity of the outcomes. All country teams started from a common (translated) topic list and indicated a trained moderator to conduct the focus groups according to common guidelines. The main focus of the analysis was the nature, the origin and the construction of the arguments on what is acceptable and feasible within the given socio-cultural context.

\section{Formal social expectations}

All 28 EU Member States have committed themselves to a number of international conventions and European legal instruments, which impose responsibilities on the Member States to secure certain individual social rights for its citizens, residents as well as individuals present on the territory. In line with the ambition of finding common ground and the overall aim of identifying a social minimum, our attention has turned primarily towards legal sources providing protection for social rights within the European context. ${ }^{35}$ In absence of a common standard within EU law guaranteeing a minimum protection of social rights, as we turn to the European Convention of Human Rights (hereafter 'the ECHR') as well as to the European Social Charter (hereafter 'the ESC'), which were accepted by the Council of Europe ${ }^{36}$. The choice to focus on the ECHR and the Charter has been made in order to, as best as possible, find a common normative basis that would facilitate a comparative analysis. Since all 28 EU Member States are parties to the ECHR we have chosen to use it as a starting point. At present, the EU and its institutions are not directly bound by the ECHR since the EU has not acceded to the ECHR. The rights of the ECHR do apply in all member states, but are not legally binding for the EU and its institutions. Even though the European Court of Justice applies the ECHR and the case law of the European Court of Human Rights (hereafter 'the ECtHR'), it does so indirectly ${ }^{37} .{ }^{38}$ The (revised) ESC, on the other hand, is not ratified by all Member States. Nevertheless, it is still an important legal instrument within the social dimension of the EU and could be seen as an already agreed upon 'normative platform' in the area of social rights $^{39}$.

Many, if not all, of the essential needs listed above can, at least at a minimum level, be said to be protected under provisions made by the ECHR as well as the ESC. For example, a

\footnotetext{
35 In this chapter we use the term "social rights" when referring to rights in areas of welfare, such as social assistance, education, health care, housing and more. We also, when discussing the ECHR, refer to 'core socioeconomic rights' as an interchangeable term to 'social rights'. For a clarifying discussion on the terminology, see I Leijten, Core Socio-Economic Rights and the European Court of Human Rights (Cambridge, CUP, 2018)., p.14 f. A longer discussion on social rights, human rights and the welfare state can be found in J King, Judging Social Rights (Cambridge, Cambridge University Press, 2012)., p. 20 ff.

${ }^{36}$ A Swiatkowski and M Wujczyk, The European Social Charter as a basis for defining social rights for EU citizens in $\mathrm{F}$ Pennings and M Seeleib-Kaiser (eds), European Citizenship and Social Rights: Entitlements and Impediments to Accessing Welfare (Cheltenham: Edward Elgar, 2018).

${ }^{37}$ Council of Europe, Accession by the European Union to the European Convention on Human Rights: Answers to frequently asked questions, (1 June 2010).

38 Since the Treaty of Lisbon, into force since December 2009, not only EU Member States are committed to the European Convention, but also the European Union has committed to acceding to the European Convention on Human Rights. The EU is obliged under Article 6(2) of the Treaty of Lisbon to accede to the ECHR.

39 S Stendahl and O Swedrup, Social Human Rights as a Legal Strategy to Enhance EU Citizenship in F Pennings and M Seeleib-Kaiser (eds), European Citizenship and Social Rights: Entitlements and Impediments to Accessing Welfare (Cheltenham, Edward Elgar, 2018).
} 
number of the needs in the list clearly relate to core socio-economic rights protected under the ECHR. To name a few; the need for adequate housing (the right to respect for the home, Article 8 of the ECHR; Article 31 of the ESC) ${ }^{40}$ and the need for accessible healthcare (the right to health care, Articles 2 and 3 of the ECHR; Articles 11 and 13 of the ESC providing the right to social and medical assistance) are both needs relating to core socio-economic rights which are recognized by the ECHR and the ESC ${ }^{41}$. In order to specify the content of these rights and further analyse to what extent the needs listed above can be seen as covered by the scope of these rights, case law of the ECtHR should be studied ${ }^{42}$ p. $233 \mathrm{ff}$.). ${ }^{43}$

In a next step, we are interested in developing a more concrete list of social positions (defined in broad terms) related to these needs, by using the same type of approach. In the process of assessing a list of core social positions, we decided to also include the Charter of Fundamental Rights of the European Union ('the Charter') as a legal source in order to further elaborate on potential common ground. The Treaty of Lisbon ensured the entry into force of the Charter, originally drafted in 2000. Insofar the Charter and the Convention include the same rights, the meaning and scope of those rights would be the same as those laid down by the Convention (Article $52 \S 3$ of the Charter). As we did for the identification of essential needs, we have also, but to a lesser extent, used the ESC to add to our understanding of core social positions.

As a starting point, the identification of a core list of social positions one should be able to take, and their related activities, goods and services should be such that they allow for a life in human dignity. As is stated by the Charter (Article 1) "Human dignity is inviolable. It must be respected and protected." In addition, institutions or social expectations that imply discrimination on any ground such as sex, race, colour, ethnic or social origin, genetic, features, language, religion or belief, political or any other opinion, membership of a national minority, property, birth, disability, age or sexual orientation should not affect the core list (cf. Articles 20-23 of the Charter). In other words, to give an example, even if dominant informal social expectations would be such that women would not work, if 'doing paid work' is on the core list, it should be there for both men and women. That being said, the core list of social positions that have been identified on the basis of the sources used, can be summarised as follows:

- Being a child, father, mother, wife or husband: Article 12 of the ECHR ('Right to marry'); Article 9 of the Charter ('Right to marry and to find a family')

- Being an employee or self-employed: Article 16 of the ECHR ('Freedom to conduct a business'); Article 15 of the Charter ('Freedom to choose an occupation and right to engage in work')

\footnotetext{
40 See also S Stendahl and O Swedrup A Legal of the Possibilities and Impediments for Citizens Seeking to Enforce their Social Rights (2016) deliverable 6.4 of the bEUcitizen project.

${ }^{41}$ See also A Swiatkowski and M Wujczyk The European Social Charter, p 13.

42 Leijten Core socio-economic rights, p. $233 \mathrm{ff}$.

43 Please note that at the EU level there are also quite a few 'soft law' initiatives that support the idea of a common understanding of the necessities for adequate social participation (including Council decisions, resolutions by the European Parliament and policy documents by the European Commission). The most recent policy framework for enhancing a decent social minimum in the EU is the European Pillar of Social Rights proclaimed by the EU Council, the Commission and the Parliament on 17 November 2017, which provides a guiding framework directly aimed at fulfilling people's essential needs and enhancing social rights for all EU citizens, including a set of 20 rights and principles.
} 
- Being a member of associations of various types, including in particular trade unions: Article 11 of the ECHR ('Freedom of assembly and association'); Article 12 of the Charter ('Freedom of assembly and of association')

- Being a student: Article 2 of the First Protocol, added to the ECHR in 1952 ('Right to education'); Article 14 of the Charter ('Right to education')

- Being an active participant in political elections, and especially a voter: Article 3 of the First Protocol, added to the ECHR in 1952 ('Right to free elections'); Articles 39 and 40 of the Charter ('Right to vote and stand as a candidate at elections to the European Parliament' \& 'Right to vote and stand as candidate at municipal elections')

- Being a citizen, more broadly speaking (Various articles throughout the Charter)

\section{Discussions in focus groups}

The abovementioned list of intermediate needs and social positions served as input for the focus groups in order to facilitate the discussion on what people need for adequate social participation. In each capital city, the country teams conducted three focus groups where they tested to what extent this list of social positions resonated with the 'well-considered views' of citizens in the $\mathrm{EU}^{44}$.

Overall, all focus groups expressed agreement with the list of social positions that was derived from legal provisions. In addition, most focus groups specified refinements of the general positions. In every focus group, the participants emphasized at least one social role related to family life, such as parent or child. For participants with children, the role of being a good parent was often said to be their most important function in life. Further, it is remarkable that nearly all focus groups agreed that everyone should be able to be an employee, and in the majority of the countries this was brought up spontaneously before showing the predefined list.

One social position that was not fully agreed upon was 'being a member of a trade union', especially in countries where trade union membership is very low. However, almost in every country 'being a member of an association' has been spontaneously identified as an essential social position or it was agreed upon when the list was shown. Especially for children, focus group members agreed upon the essential need to belong to a social network. Further, for children as well as for adults, the position of a student was in all countries considered essential, and the use of digital media was stressed as crucial in this regard. Finally, being a voter and citizen was brought up by nearly all focus groups as crucial social positions. In many focus groups, participants argued that a more politically or socially active role should be stressed such as an active or engaged citizen, a volunteer, an activist or an opposition member.

There were also social positions that were considered essential in various focus groups, while not identified on the basis of our reading of the European Convention or the Charter:

- Being a friend and being a neighbour

44 'Well-considered' in this context means: views expressed in a dialogue (discussion) with others, with some time for reflection and potential to revise one's views at the end of the discussion. 
- Caring roles (caregiver as an adult for the parents, homemaker, pet carer, patient), especially within the family context as caring and being cared for, but also as an insurance taker or a patient within health care institutions.

- Several educational positions such as a (social) media user/producer, an educator/teacher (also as a parent), a classmate and a member of a parent association.

- Positions within the domain of leisure were mentioned such as a consumer of culture, a traveller, a hobbyist and a sports(wo)man.

- Being a member of local communities such as municipalities, cities and apartment councils or of bigger entities such as Europe.

- The role of a consumer or customer. It was noted that consuming is an essential part of participation in modern society.

- Being a member of a religious group or some other kind of like-minded ideological group was seen as an essential social position for one's autonomy and identity.

It would be interesting to see whether in a new round of focus group discussions participants from all EU countries would support the inclusion of these additional positions to the list of essential positions. In any case, on this ground we can tentatively conclude that at least in these focus groups there was quite some common understanding across EU capitals of a core group of social positions that people should be able to take in order to participate adequately in society.

After the discussions on essential social positions, the focus groups were asked which activities and goods and services should be provided at the minimum in order to fulfil these social positions adequately. Subsequently, these concrete items were grouped into larger categories of needs. Finally, the predefined list of essential needs was shown in all focus groups to check whether these categories were acceptable or if they should be adjusted and why. In other words, the main aim was not to draft a complete list of goods and services, but to use them as examples to derive inductively a list of more abstract needs that should be fulfilled. Again, we found that there was general agreement on the importance of all the needs listed above. The more physical needs for food, clothing, adequate housing and personal and health care were seen as self-evident without evoking much of discussion. As regards clothing, focus groups in some countries argued how this is related to various informal social expectations. Also with regard to the need for mobility and security there seemed to be strong agreement in the focus groups across EU cities. It is worthwhile stressing that when discussing the need for security, participants stressed the need for financial security through insurances, income, pensions and bank accounts, but also entitlement to social rights, a social safety net of friends and relatives, access to services, legal protection and employment regulation were often mentioned as part of this need.

Besides the more physical needs, the focus groups across all countries emphasized also the importance of social relations, education, leisure time and employment, albeit with large socio-cultural differences between countries. The most important element with respect to social relations that came back across many discussion groups was the need for communication, especially through digital (social) media. However, this provoked also lots of discussion, for example regarding whether or not a smartphone or a personal computer are minimum necessities. The need for internet and a mobile phone were also considered essential in many cases for fulfilling the need for information. The participants often pointed out that everyone should be able to inform himself or herself through television, newspaper, the library and especially by making use of the internet. Moreover, the need for communication and information, in particular through the use of digital media, was according to some focus groups (in BE, EL, DE, DK, IT, FI, MT, PT) not represented well enough by the other categories 
of needs. Yet, only a few groups suggested creating a separate category. Also rest and leisure is seen as an essential need in nearly all countries. In various countries people with a relatively low income as well as people with higher socio-economic positions argued that they face problems of limited time to fulfil their needs for rest and leisure, to maintain social relations, and to combine work and family life. Especially for single parent families or for parents working full time, there is often lack of time to properly fulfil these needs. In this context, accessible and affordable child care was indicated as an important service to which people should have sufficient access.

In all countries, focus groups agreed with the need for a safe childhood. Education was especially highlighted, and in some countries, it was even appointed as a distinct need. The focus groups emphasized that in order to be a good parent one should be able to take care of children and provide them a safe, supportive environment with affordable, accessible and good quality services such as education and child care, but also sport clubs or youth movements, (free) public transport, health care and infrastructure (eg playgrounds). For instance, when public schools lack quality or when the access is limited, people need more financial means to provide an adequate educational level for their children (eg through private alternatives).

In the majority of the countries the focus group participants argued that not only children but also adults should be able to engage in a process of lifelong learning. However, in a few focus groups, the concept of lifelong learning evoked some disagreement. When it was formulated in a less formalized sense, but rather as keeping up with progress in society or learning new things, most focus groups agreed that it should be an essential need. Finally, in all countries, focus groups highlighted the need for decent work. In the list of intermediate needs based on the Theory of Human Need, employment was not identified as a distinct intermediate need. However, there seemed to be general agreement in the focus groups across countries to identify access to decent work as a separate essential need in order to stress the importance of having a job for adequate social participation. Another additional category of essential needs that came back frequently in the focus group discussions across different countries, is the need for active participation and involvement in society. This was often related to the essential social position of being an active and entitled citizen (social rights and freedoms) who needs political representation and involvement. These two additions to the list of essential needs merit more attention in the future.

\section{Conclusion}

Valid comparative assessments of the adequacy of the minimum income protection provided by European welfare states could boost efforts by policy makers to guarantee adequate incomes throughout the EU. Such assessments require a monetary benchmark that is comparable across countries. The more such a benchmark relies on a common normative understanding of what 'adequacy' means, the more convincing it will be for evaluating the adequacy of minimum income standards across the EU. In this chapter, we explored whether there is sufficient common ground for a shared normative understanding of what adequacy means in more concrete terms. To do so, we started from the concept of adequate social participation, which we defined as the ability of people to adequately play (take and make) the various social roles one should be able to play as a member of society. This notion of adequate social participation was further developed in dialogue with the Theory of Human Need and some insights from the capability theory. Essential needs that should be fulfilled for adequate social participation include access to adequate housing, clothing, an adequate diet, personal hygiene and health care, rest and leisure, the means for maintaining significant social relations, security in childhood, mobility, security and lifelong learning. Subsequently, 
we explored whether across Europe there is some common understanding of what adequate social participation means and what needs should be fulfilled in order to be able to participate adequately in society.

On the basis of a brief review of international standards as well as a series of over 65 focus group discussions in $24 \mathrm{EU}$ capital cities, we conclude that at least at an abstract level, there is sufficient common ground for a European understanding of 'adequate social participation' and for defining the needs that should be fulfilled. More in particular, we found that many of these needs resonate well with 'formal social expectations' as embedded in the European Convention of Human Rights and the European Social Charter. However, not all of the needs for adequate social participation are mentioned by these international legal sources. Yet, with very few exceptions the focus groups supported the relevance of each of these needs for adequate social participation. Furthermore, several discussion groups found that some needs were missing from the theoretical framework, including access to decent work and an active (political) participation and involvement in society. In addition, in quite a few countries it was stated that the importance of access to communication technologies and information should be emphasized more strongly. In addition, based on the European Convention and the Charter, we outlined a list of essential social positions that people should be able to take in the context of adequate social participation. Such a list helps to specify a common understanding of adequate social participation and to identify the required resources for adequately fulfilling the formal and informal social expectations associated with these positions (ie their social roles). Subsequently, we asked participants in discussion groups to reflect on what they consider essential social positions that people should be able to take as a member of their society. The results of these discussions suggest that there is quite some common understanding of what adequate social participation entails in these terms, even though several refinements and additions to the list of essential positions were suggested by some discussion groups.

Further research, including a new round of discussions and, preferably, involving sufficiently large random samples of respondents are required to assess to what extent these additional suggestions resonate with the well-considered views of citizens across Europe. In addition, also formal social expectations could be studied in a much more extensive form, for instance by also consulting other European legal sources, but also by exploring to what extent national legislation converges (and diverges) with regard to essential features of what can be considered adequate social participation. Such an analysis should go further than assessing which needs and social positions are essential, and analyse the formal expectations regarding the social roles that people should be able to play at a minimum as a member of society. For instance, what are the formal expectations regarding parents and citizens? What are the implications of these expectations for the goods and services to which individuals and households must have access in order to be able to live up to these expectations? Such an analysis, especially if undertaken jointly by legal scholars and social scientists in a transdisciplinary research context, would be a next fruitful step in developing well-founded reference budgets with a strong empirical basis.

We consider the findings presented in this chapter to be promising in view of developing a meaningful comparative benchmark for cross-national monitoring of income adequacy. First results of developing such a benchmark have already led to new insights (eg Carrillo, et al., 2018; Goedemé et al., 2019), but, clearly, the development of comparable reference budgets is still in its infancy, with quite some room for innovative research on a very challenging topic.

\section{References}

Ágh, A, 'The Decline of Democracy in East-Central Europe',(2016) Problems of PostCommunism, 63, 277. 
Alkire, S, 'Dimensions of Human Development',(2002) World Development, 30, 181.

Atkinson, AB, Cantillon, B, Marlier, E and Nolan, B, Social Indicators: The EU and Social Inclusion (Oxford, Oxford University Press, 2002).

Biddle, BJ, 'Recent Developments in Role Theory',(1986) Annual Review of Sociology, 12, 67.

Bilchitz, B, Poverty and Fundamental Rights, (Oxford, OUP, 2007)

Brinks, B, Gauri, V and Shen, K, 'Social Rights Constitutionalism: Negotiating the Tension Between the Universal and the Particular' (2015) Annual Review of Law and Social Science, 11, 289.

Cantillon, B, Goedemé, T and Hills, J (eds), Decent Incomes for All. Improving Policies in Europe (New York: Oxford University Press, 2019).

Carrillo-Álvarez, E, Penne, T, Boeckx, H, Storms, B and Goedemé, T, 'Food Reference Budgets as a Potential Policy Tool to Address Food Insecurity: Lessons Learned from a Pilot Study in 26 European Countries',(2019) International Journal of Environmental Research and Public Health, 16, 32.

Cervero-Liceras, F, McKee, $\mathrm{M}$ and Legido-Quigley, $\mathrm{H}$, 'The Effects of the Financial Crisis and Austerity Measures on the Spanish Health Care System: A Qualitative Analysis of Health Professionals' Perceptions in the Region of Valencia',(2015) Health Policy, 119, 100.

Coleman, D and Isoahola, SE, 'Leisure and Health - the Role of Social Support and SelfDetermination',(1993) Journal of Leisure Research, 25, 111.

Doyal, L and Gough, I, A Theory of Human Need (Houndmills, Macmillan, 1991).

Goedemé, T, Penne, T, Hufkens, T, Karakitsios, A, Bernát, A, Franziskus, A, Simonovits, B, Álvarez, EC, Kanavitsa, E, Cussó Parcerisas, I, Romaní, JR, Mäkinen, L, Matsaganis, M, Arlotti, M, Kopasz, M, Szivós, P, Ritakallio, V-M, Kazepov, Y, Van den Bosch, K and Storms, B, 'What Does It Mean to Live on the Poverty Threshold? Lessons from Reference Budgets', in B Cantillon, T Goedemé and J Hills (eds), Decent Incomes for All. Improving Policies in Europe (New York: Oxford University Press, 2019).

Goedemé, T, Storms, B, Penne, T and Van den Bosch, K, The Development of a Methodology for Comparable Reference Budgets in Europe - Final Report of the Pilot Project, Pilot Project for the Development of a Common Methodology on Reference Budgets in Europe (Contract No. Vc/2013/0554), (Brussels, European Commission, 2015).

Goedemé, T, Storms, B, Stockman, S, Penne, T and Van den Bosch, K, 'Towards CrossCountry Comparable Reference Budgets in Europe: First Results of a Concerted Effort',(2015) European Journal of Social Security (EJSS), 17, 3.

Gough, I, 'Lists and Thresholds: Comparing the Doyal-Gough Theory of Human Need with Nussbaum's Capabilities Approach', in F Comim and MC Nussbaum (eds), Capabilities, Gender, Equality: Towards Fundamental Entitlements (Cambridge: Cambridge University Press, 2014).

Keramidou, I and Triantafyllopoulos, L, 'The Impact of the Financial Crisis and Austerity Policies on the Service Quality of Public Hospitals in Greece',(2018) Health Policy, 122, 352.

King, J, Judging Social Rights (Cambridge, Cambridge University Press, 2012).

Leijten, I, Core Socio-Economic Rights and the European Court of Human Rights (Cambridge, CUP, 2018). 
Mau, S and Verwiebe, R, European Societies. Mapping Structure and Change (Bristol, The Policy Press, 2010).

Nagata, J, 'Plural Societies', in NJSB Baltes (ed), International Encyclopedia of the Social \& Behavioral Sciences (Oxford: Pergamon, 2001).

Nussbaum, MC, Women and Human Development: The Capabilities Approach (Cambridge, Cambridge University Press, 2000).

Platt, GM, 'Status and Role, Social Psychology Of', in NJSB Baltes (ed), International Encyclopedia of the Social \& Behavioral Sciences (Oxford: Pergamon, 2001).

Sen, A, 'Capability and Well-Being', in MC Nussbaum and A Sen (eds), The Quality of Life (Oxford: Clarendon Press, 1993).

Sen, A, Choice, Welfare and Measurement (Oxford, Blackwell, 1982).

Sen, A, 'Poor, Relatively Speaking',(1983) Oxford Economic Papers, 35, 153.

Sen, A, The Standard of Living (Cambridge, Cambridge University Press, 1987).

Stendahl, S and Swedrup, O, A Legal of the Possibilities and Impediments for Citizens Seeking to Enforce their Social Rights (2016) deliverable 6.4 of the bEUcitizen project.

Stendahl, S and Swedrup, O, 'Social Human Rights as a Legal Strategy to Enhance Eu Citizenship', in F Pennings and M Seeleib-Kaiser (eds), European Citizenship and Social Rights: Entitlements and Impediments to Accessing Welfare (Cheltenham: Edward Elgar, 2018).

Storms, B, Goedemé, T, Van den Bosch, K and Devuyst, K, Towards a Common Framework for Developing Cross-Nationally Comparable Reference Budgets in Europe, ImPRovE Working Papers, (Antwerp, Herman Deleeck Centre for Social Policy - University of Antwerp, 2013).

Storms, B, Goedemé, T, Van den Bosch, K, Penne, T, Schuerman, N and Stockman, S, Review of Current State of Play on Reference Budget Practices at National, Regional, and Local Level, (Brussels, European Commission, 2014).

Storms, B, Referentiebudgetten Voor Maatschappelijke Participatie [Reference Budgets for Social Participation], (PhD thesis, Antwerp, University of Antwerp, 2012).

Swiatkowski, A and Wujczyk, M, 'The European Social Charter as a Basis for Defining Social Rights for Eu Citizens', in F Pennings and M Seeleib-Kaiser (eds), European Citizenship and Social Rights: Entitlements and Impediments to Accessing Welfare (Cheltenham: Edward Elgar, 2018).

Van den Bosch, K, Goedemé, T, Schuerman, N and Storms, B, 'Reference Housing Costs for Adequate Dwellings in Ten European Capitals',(2016) Critical Housing Analysis, 3, 1.

Voss, TR, 'Institutions', in NJSB Baltes (ed), International Encyclopedia of the Social \& Behavioral Sciences (Oxford: Pergamon, 2001).

Vrooman, CJ, Rules of Relief. Institutions of Social Security, and Their Impact (The Hague, SCP, 2009).

WHO, Manuals on Child Mental Health and Psychosocial Development (Geneva, WHO, 1982).

Young, KG, 'The Minimum Core of Economic and Social Rights: A Concept in Search of Content', Yale Journal of International Law (2008), 33, No. 1. 